\title{
Studi penyebaran populasi dan daya dukung habitat Kuskus Beruang (Ailurops ursinus) di Pulau Manado Tua Sulawesi Utara
}

\author{
H.J. Kiroh*, M.J. Hendrik, F.S. Ratulangi, S.C. Rimbing \\ Fakultas Peternakan Universitas Sam Ratulangi Manado \\ Korespondensi (Corresponding author): hengkijohanis.26@gmail.com
}

\begin{abstract}
ABSTRAK
Pulau Manado Tua menyimpan berbagai keanekaragaman hayati yang langka endemik seperti kuskus beruang (Ailurops ursinus), kuskus kerdil (Strigocuscus celebensis), monyet hitam (Macaca nigra), Tangkasi (Tarsius spectrum)serta beberapa jenis tumbuhan langka seperti lengkuas hutan (Alpina sp.) dan pandan hutan (Pandanus sp.) yang semuanya perlu mendapat perlindungan secara intensif.Tujuan penelitian ialah untuk mempelajari sebaran populasi dan daya dukung habitat kuskus di pulau Manado Tua I dan II, serta sebagai paket rekomendasi model konservasi yang sesuai dengan keadaan wilayah bagi Pemerintah Daerah. Variabel yang diamati dalam penelitian ini adalah kepadatan dan tingkat populasi kuskus kerdil serta daya dukung habitat yaitu vegetasi tumbuhan baik tingkat pohon, sapihan/semai.Data yang diperoleh dianalisa dan untuk populasi satwa menggunakan Metode Line Transect (Transek garis). Sedangkan Analisa Vegetasi diolah dan dihitung nilai Indeks pentingnya dari masingmasing jenis pohon (INP). Hasil penelitian menunjukkan bahwa di Pulau Manado Tua I terdapat \pm kuskus kerdil (Strigocuscus celebensis) sebesar 295 ekor dan kuskus beruang (Ailurops Ursinus) sebesar 49 ekor. Sedangkan Manado Tua II diperkirakan terdapat sejumlah kuskus dimana kuskus kerdil (Strigocuscus celebensis) \pm 305 ekor dan kuskus beruang (Ailurops Ursinus) \pm 57 ekor. Sedangkan daya dukung habitat untuk vegetasi tingkat pohon sebesar indeks nilai pentingnya mencapai (INP) $\pm 298,65 \%$ dan untuk tingkat sopihan indeks nilai pentingnya (INP) $\pm 300,68 \%$ yang berarti daya dukung habitat untuk kehidupan kuskus di Pulau Manado Tua sangat baik. Kesimpulan bahwa populasi satwa endemik kuskus kerdil masih ditemukan di Pulau Manado Tua I dan II, namun populasinya semakin menurun akibat pengrusakan daya dukung habitatnya dan penangkapan yang tak terkendali oleh masyarakat.
\end{abstract}

Kata kunci: daya dukung habitat, kuskus kerdil, kuskus beruang

\section{ABSTRACT}

STUDY OF SPREADING POPULATION AND HABITAT CARRYING CAPACITY OF THE SULAWESI BEAR CUSCUS (Ailurops ursinus) AT MANADO TUA ISLAND OF NORTH SULAWESI. Manado Tua Island is still keeping the endemic Sulawesi bear cuscus (Ailurops ursinus), dwarf cuscus (Strigocuscus celebensis), black macaque (Macaca nigra), tarsius (Tarsius spectrum) as well as some kinds of plant biodiversity including forest galangal (Alpina sp.) and forest pandanus (Pandanus sp.), all should be protected intensively. Objective of this study was to evaluate spreading population and habitat carrying capacity of bear cuscus (Ailurops ursinus) at the Island of Manado Tua I and II, to be used for recommendation package of conservation model on the base of administrative condition of Manado governmental areas. The Variables observed in this study were population density of bear cuscus and dwarf cuscus as well as their habitat carrying capacity of plant vegetation including categories of try, bush, thicket and seedling levels. Data of wild animals were found by Line Transect Method. Plant vegetations were calculated based on the important index values of each category level. Result showed that Manado Tua I Island was inhabited by dwarf 
cuscus (Strigocuscus celebensis) of about 295 heads and bear cuscus (Ailurops Ursinus) of about 49 heads. Manado Tua II Island was inhabited by dwarf cuscus (Strigocuscus celebensis) of about 305 heads and bear cuscus (Ailurops Ursinus) of about 57 heads. Habitat carrying capacity of try vegetation level of the important index values was about 298,65\% and seedling vegetation level of about $300,68 \%$. These mean that carrying capacity was supporting the conservation for both kinds of cuscus in Manado Tua Island. These population of the endemic wild animals in Manado Tua I dan II Islands should be protected as their habitat area was degrading due to uncontrol illegal logging and hunting by local community.

Keywords: habitat carrying capacity, dwarf cuscus, bear cuscus

\section{PENDAHULUAN}

Pulau Manado Tua merupakan salah
satu pulau yang masuk wilayah Pemerintahan Kota Manado. Pulau ini sangat berdekatan dengan Pulau Bunaken yang menjadi Pusat Konservasi Taman Laut terkenal di Indonesia bahkan dunia sehingga menjadi daya tarik tersendiri. Menurut Maramis et al. (2020), bahwa Indonesia merupakan negara kepulauan terbesar di dunia yang terdiri dari 16.344 pulau besar dan kecil dengan panjang garis pantai $81.000 \mathrm{~km}$ serta memiliki kekayaan keragaman hayati yang tinggi dan juga memiliki ekositem laut yang sangat khas. Tanpa disadari ternyata di wilayah ini juga menyimpan berbagai keanekaragaman hayati yang langka endemik seperti kuskus beruang (Ailurops ursinus), kuskus kerdil (Strigocuscus celebensis), monyet hitam (Macaca nigra), tangkasi (Tarsius spectrum) serta beberapa jenis tumbuhan langka seperti lengkuas hutan (Alpina $s p$ ) dan pandan hutan (Pandanus sp) yang semuanya perlu mendapat perlindungan secara intensif. Genus-genus Kuskus yang ditemukan di Indonesia sangat bervariasi seperti yang disampaikan oleh Sara et al. (2016) bahwa di Maluku ditemukan dua genus Kuskus yaitu Phalanger dan Spilocuscus, hal ini hampir sama dengan apa yang dikatakan Handayani dan Kunda (2019), bahwa di Indonesia kuskus yang ditemukan berasal dari genus Ailurops, Phalanger, Spilocuscus dan Strigocuscus dan menyebar secara terbatas hanya di Indonesia Bagian Timur. Selanjutnya dikatakan oleh Handayani dan Kunda
(2019), dibutuhkan studi untuk mengidentifikasi jenis pakan kuskus pada habitat alami, yang diharapkan dapat membantu usaha konservasi satwa ini di masa mendatang. Saroyo et al. (2019) menyatakan bahwa kawasan yang menyimpan kekayaan hayati endemik Sulawesi telah berstatus sebagai kawasan konservasi antara lain Cagar alam Dua Saudara Taman Wisata Batuputih dan Taman Wisata Batuangus Kota Bitung Sulawesi Utara.

Namun disayangkan dari tahun ke tahun keberadaan flora dan fauna endemik ini terancam punah, akibat eksploitasi hutan secara berlebihan. Di lain pihak maraknya pembukaan lahan baru untuk lokasi perkebunan oleh masyarakat setempat, serta masih membudayanya penduduk Pulau Manado Tua dan sekitarnya melakukan perburuan satwa-satwa endemik secara tak terkendali. Kebiasaan inilah menyebabkan populasi satwa dari hari kehari semakin menurun. Hal ini juga sebagaimana yang disampaikan oleh Darenoh et al. (2019), bahwa ancaman bagi Kuskus Beruang adalah hilangnya sebagian habitat yang disebabkan oleh penebangan hutan untuk lahan pertanian skala kecil maupun yang berskala besar. Jika hal ini tidak cepat ditangani, maka dikuatirkan semua satwa yang dijumpai di Pulau Manado Tua akan mengalami kepunahan. Agar tidak terjadi kepunahan yang akan menghilangkan salah satu kekayaan alam sulawesi bahkan nasional yaitu kuskus kerdil (Strigocuscus celebensis) di Pulau Manado Tua maka salah satu strategi yaitu memahami secara komprehensif satwa 
tersebut mulai dari tingkat populasi dan daya dukung habitat sampai pada teknik penangkaran dan budidayanya. Upayaupaya ini selaras dengan apa yang disampaikan oleh Saragih et al. (2010), bahwa Kuskus Beruang di Indonesia sudah dilindungi sejak tahun 1990 melalui Peraturan Perburuan Binatang Liar (PPBL) dengan No. 226/1931 dan UU Nomor 7 tahun 1999 tentang Pengawetan jenis Tumbuhan dan Satwa. Berdasarkan hal-hal tersebut, diperlukan suatu penelitian ilmiah karena mengingat masih kurangnya informasi ilmiah tentang populasinya dan upaya konservasi maka akan dilakukan penelitian di Pulau Manado Tua dengan harapan dapat mengatasi kepunahan satwa endemik tersebut.

\section{MATERI DAN METODE PENELITIAN}

Penelitian ini dilaksanakan di hutan Pulau Manado Tua yaitu di wilayah hutan Kelurahan Manado Tua I dan II. Pengambilan data dilakukan sejak tanggal 17 Agustus sampai dengan 17 Oktober 2020. Pengumpulan data untuk mengetahui populasi satwa digunakan Metode Line Transect (Transek garis) (Alikodra, 2018). Pengukuran vegetasi menggunakan metode kuadrat dengan cara jalur berpetak (Ruslan, 1986).

Transek dibuat pada lokasi yang telah ditentukan dengan pertimbangan mengikuti pola pergerakan satwa. Panjang transek disesuaikan dengan luas habitat yang diwakili, dimana semakin luas habitat yang diwakili maka semakin panjang transek yang dibuat. Dalam penelitian ini dibuat transek yang panjangnya $1.500 \mathrm{~m}$ dan dibagi dalam 3 transek yaitu Transek $\mathrm{A}=$ $600 \mathrm{~m}$ dataran rendah, Transek $B=500 \mathrm{~m}$ dataran sedang, Transek $\mathrm{C}=400 \mathrm{~m}$ dataran tinggi. Setiap jarak $50 \mathrm{~m}$ dilakukan penandaan dengan menggunakan pita.

Peralatan yang digunakan dalam penelitian ini antara lain teropong (binokuler), kompas, altimeter, jam, pita transek, tali, roll meter, photo kamera, buku petunjuk lapangan, ATK.

Variabel yang diamati jumlah individu yang teramati, waktu penemuan dan lokasi penemuan dalam transek serta kepadatan populasi spesies Kuskus kerdil (Strigocuscus celebensis). Pengukuran vegetasi menggunakan metode kuadrat dengan cara jalur berpetak (Ruslan, 1986). Sepanjang jalur dibuat petak-petak dengan ukuran masing-masing (a) $20 \times 20$ m untuk menganalisa tumbuhan tingkat pohon, (b) $10 \times 10 \mathrm{~m}$ untuk analisa tumbuhan tingkat tiang, (c) $5 \times 5 \mathrm{~m}$ untuk menganalisa tumbuhan tingkat sapihan, (d) $2 \times 2$ m untuk menganalisa tumbuhan tingkat semai.

Dalam pengambilan data vegetasi maka penempatan setiap titik petak ditentukan secara sistematik. Jarak antara setiap petak $150 \mathrm{~m}$ dan setiap tumbuhan yang ada dalam petak pengamatan dicatat kehadirannya dan untuk petak ukuran $20 \mathrm{x}$ $20 \mathrm{~m}$ dan $10 \times 10 \mathrm{~m}$ diukur lingkar batang tumbuhan tersebut.

Data populasi satwa akan dianalisa dengan menggunakan metode Sunarto (1996) dengan rumus :

$P=\frac{\text { A.S }}{\text { S.L.D }}$

Keterangan :

$\mathrm{P}=$ Populasi

$\mathrm{A}=$ Luas areal seluruhan yang disensus

$\mathrm{S}=$ Jumlah satwa yang ditemukan selama pengamatan

$\mathrm{L}=$ Panjang jalur

$\mathrm{D}=$ Jarak rata-rata pengamat dan satwa

Hasil analisa vegetasi akan diolah dan dihitung nilai indeks pentingnya dari masing-masing jenis pohon. Nilai indeks penting merupakan hasil penjumlahan dari Kerapatan relatif (KR), Frekuensi relatif (FR), dan Dominasi relatif (DR) menurut Ruslan (1986). Parameter vegetasi yang diukur adalah nama jenis, diameter dan jumlah tiap jenis dalam petak pengamatan.

$\operatorname{Kerapatan}(K)=\frac{\text { Jumlah } \text { individu suatu spesies }}{\text { Luas petak cintoh }}$ 
$\mathrm{KR}=\frac{\text { Kerapatan suatu spesies }}{\text { Kerapatan seluruh spesies }} \times 100 \%$

Frekwensi $(F)$

$=\frac{\text { Jumlah sub petak ditemukan suatu spesies }}{\text { jumlah seluruh sub petak contoh }}$

$\mathrm{FR}=\frac{\text { Frekuensi suatu spesies }}{\text { Frekuensi seluruh spesies }} \times 100 \%$

Dominasi $(D)=\frac{\text { Luas bidang dasar suatu spesies }}{\text { Luas petak contoh }}$

$\mathrm{DR}=\frac{\text { Dominasi suatu spesies }}{\text { KDominasi seluruh spesies }} \times 100 \%$

\section{HASIL DAN PEMBAHASAN}

\section{Letak geografis dan topografi Pulau Manado Tua}

Kota Manado terletak di ujung utara

Pulau Sulawesi dan merupakan kota terbesar di belahan Sulawesi Utara sekaligus sebagai ibukota Propinsi Sulawesi Utara. Secara geografis terletak di antara 10 25' 88" - 10 39' 50" LU dan 1240 $47^{\prime} 00^{\prime \prime}$ - 1240 56' 00" BT., dan secara administratif batas-batasnya sebagai berikut:

a. Sebelah Utara Kabupaten Minahasa Utara

b. Sebelah Timur Kabupaten Minahasa Utara dan Kabupaten Minahasa

c. Sebelah Selatan Kabupaten Minahasa

d. Sebelah Barat Laut Sulawesi

Wilayah kota Manado terdiri dari wilayah daratan dan wilayah kepulauan dengan luas keseluruhan 15.726 ha. Wilayah kepulauan meliputi pulau Bunaken, pulau Manado Tua dan pulau Siladen. Kondisi topografi dan geomorfologinya merupakan bagian dari gugusan pegunungan, perbukitan, lembah dan sungai yang berada di daratan Minahasa. Bagian utara bermorfologi berbukit sampai bergunung dengan puncak tertinggi Gunung Tumpa, $610 \mathrm{~m}$. Di bagian timur umumnya bergelombang dengan morfologi landai sampai curam, dan mendekati bagian tengah kota, morfologi semakin landai dan rata. Pada bagian selatan, punggung-punggung bukit semakin melebar dan menjalar lebih panjang. Topografi kota Manado bervariasi antara $0 \%$ hingga lebih dari $40 \%$ yang secara keseluruhan $94,53 \%$ terletak pada ketinggian 0-240 m dpl.

Kota Manado mempunyai 3 wilayah pulau yang berpenghuni, yaitu Pulau Manado Tua, Pulau Bunaken dan Pulau Siladen dimana garis pantai Kota Manado sepanjang 57,09 km terdiri dari garis pantai di Wilayah Daratan 24,91 km dan 32,18 km garis pantai di Pulau Bunaken, Manado Tua, dan Siladen. Adapun luas dan panjang garis pantai dari masing-masing pulau dapat dilihat pada Tabel 2. Pulau Manado Tua Memiliki Luas Wilayah terbesar yaitu 1.028,27 ha dengan panjang garis pantai $12,174 \mathrm{~km}$, Pulau Bunaken 804,56 ha dan memiliki garis pantai terpanjang yaitu 17,079 km serta Pulau Siladen dengan luas wilayah terkecil 49,48 ha dan garis pantai $2,928 \mathrm{~km}$.

Tabel 1. Luas Wilayah Kota Manado menurut Wilayah Daratan dan Kepulauan

\begin{tabular}{lccl}
\hline \multicolumn{1}{c}{ Nama pulau } & Luas & $\begin{array}{c}\text { Panjang garis } \\
\text { pantai }\end{array}$ & \multicolumn{1}{c}{$\begin{array}{l}\text { Kelurahan/Kecamatan } \\
\text { Manado Tua }\end{array}$} \\
$1.056,02$ & 12.280 & $\begin{array}{l}\text { Manado Tua Satu dan } \\
\text { Manado Tua Dua Kec. } \\
\text { Bunaken }\end{array}$ \\
Bunaken & 811,21 & 17.570 & $\begin{array}{l}\text { Bunaken dan Alung Banua } \\
\text { Kec. Bunaken } \\
\text { Bunaken Kec. Bunaken }\end{array}$ \\
\hline
\end{tabular}

Sumber : BPN Kota Manado 
Tabel 2. Nama Pulau, Luas, dan Panjang Garis Pantai

\begin{tabular}{lcc}
\hline Pulau & Luas (ha) & Panjang Garis Pantai $(\mathrm{km})$ \\
\hline Manado Tua & $1.028,27$ & 12,174 \\
Bunaken & 804,56 & 17,079 \\
Siladen & 49,48 & 2,928 \\
\hline
\end{tabular}

Sumber : Bappeda Kota Manado, Tahun 2009

\begin{abstract}
Geomorfologi Kota Manado merupakan bagian dari gugusan pegunungan, perbukitan, lembah dan sungai yang berada di tanah Minahasa. Manado bagian Utara bermorfologi berbukit sampai bergunung, bagian timur umumnya bergelombang dengan morfologi landai sampai curam, dan mendekati bagian tengah Kota Manado morfologinya semakin landai dan rata. Bagian selatan punggung-punggung bukit semakin melebar dan menjalar lebih panjang. Bagian kepulauan terdapat Pulau Manado Tua, Pulau Bunaken dan Pulau Siladen. Morfologi Pulau Manado Tua adalah gunung berapi muda dengan ketinggian lebih dari 750 meter, Pulau Bunaken dan Pulau Siladen bergelombang dengan ketinggian 200 meter.
\end{abstract}

\section{Potensi Kuskus Kerdil (Strigocuscus celebensis) di Pulau Manado Tua}

Hasil pengamatan di lapangan menunjukkan bahwa di Pulau Manado Tua menyimpan kekayaan fauna endemik yaitu kuskus kerdil (Strigocuscus celebensis) dan juga kuskus beruang (Aillurops ursinus). Kedua jenis Kuskus ini tersebar di Pulau Manado Tua di wilayah yaitu Kelurahan Manado Tua I dengan perkiraan populasi jenis Kuskus kerdil (Strigocuscus celebensis) lebih sedikit dibandingkan dengan Kelurahan Manado Tua II. Daya dukung habitat yang masih sangat baik menyebabkan penyebaran kuskus kerdil ini mampu bertahan hidup dengan leluasa di Kelurahan Manado Tua II di banding Kelurahan Manado Tua II. Darenoh et al. (2019) menyatakan bahwa salah satu jenis satwa liar yang tergolong mamalia berkantung dan endemik Sulawesi adalah Kuskus Beruang (Ailurops ursinus), serta banyak di temukan di Indonesia bagian timur seperti: Papua (Irian Jaya), Sulawesi, Maluku dan Pulau Timor. Hasil pengamatan dilapangan terlihat aktifitas makan Kuskus Beruang disaat mereka lapar dengan prilaku-prilaku yang diperlihatkan. Hal ini sejalan dengan Schelinck et al. (2010), bahwa aktifitas makan yang dilakukan oleh satwa liar adalah disaat mereka merasa lapar dengan prilaku khasnya yang tujuannya untuk memenuhi kebutuhan hidupnya. Sebaran dan jenis kuskus pada lokasi penelitian di Pulau Manado Tua dapat dilihat pada Tabel 3. Hasil perhitungan menunjukkan bahwa Kuskus yang ditemukan di Pulau Manado Tua populasinya berfluktuasi dimana di Kelurahan Manado Tua I diperkirakan populasi kuskus kerdil (Strigocuscus celebensis) mencapai \pm 295 ekor dan kuskus beruang (Aillurops ursinus) mencapai \pm 49 ekor dengan total Kuskus kerdil dan kuskus beruang diperkirakan tinggal 394 ekor. Satwa ini biasanya aktif dan berkeliaran untuk mencari makanan pada jam-jam tertentu yaitu jam 18.00 wita di pucuk pohon sehingga disebut hewan "Aboreal" dan hidup secara berpasangan (Kiroh dan Gultom, 2005). Sedangkan Usmany dan Kakisina (2018), mengatakan bahwa ternyata kuskus tergolong jenis hewan pemakan tumbuhan (herbivoral), satwa yang marsupial herbivoral yang memanfaatkan tumbuhan sebagai makanan dan tumbuhan yang biasanya di konsuminya bukan hanya tumbuhan muda, tetapi juga berupa buah-buahan. Pernyataan ini di perkuat juga oleh Sara et al. (2020), jenis pakan yang biasa yang di manfaatkan Kuskus Beruang di cagar alam Tangale diantaranya randu (Ceiba patandri gaertn) yang masuk family Malvaceae, dan yang 
Tabel 3. Jumlah dan Sebaran Kuskus di Lokasi Penelitian

\begin{tabular}{|c|c|c|c|c|c|}
\hline No & Lokasi Pengamatan & $\begin{array}{l}\text { Jalur } \\
\text { Pengamatan } \\
\text { Satwa }\end{array}$ & Jenis Kuskus & $\begin{array}{c}\mathrm{S} \\
\text { (ekor) }\end{array}$ & $\begin{array}{c}\text { P } \\
\text { Petak Jalur } \\
\text { Pengamatan }\end{array}$ \\
\hline \multirow[t]{6}{*}{1} & \multirow[t]{6}{*}{ Kelurahan Manado Tua I } & $\mathrm{A}$ & K. kerdil & 75 & 32 \\
\hline & & & K. beruang & 21 & 11 \\
\hline & & B & K. kerdil & 125 & 72 \\
\hline & & & K. beruang & 15 & 7 \\
\hline & & $\mathrm{C}$ & K. kerdil & 95 & 45 \\
\hline & & & K. beruang & 13 & 7 \\
\hline \multirow[t]{6}{*}{2} & \multirow[t]{6}{*}{ Kelurahan Manado Tua II } & A & K. kerdil & 90 & 42 \\
\hline & & & K. beruang & 15 & 8 \\
\hline & & $\mathrm{B}$ & K. kerdil & 135 & 58 \\
\hline & & & K. beruang & 22 & 14 \\
\hline & & $\mathrm{C}$ & K. kerdil & 90 & 45 \\
\hline & & & K. beruang & 20 & 13 \\
\hline
\end{tabular}

Keterangan : Jalur $\mathrm{A}=6000 \mathrm{~m}$ dataran rendah Jalur B $=5000 \mathrm{~m}$ dataran sedang Jalur $\mathrm{C}=4000 \mathrm{~m}$ dataran tinggi dimakan adalah bagian batang dan daun muda bagian pucuknya di pohon. Satwa ini juga memakan buah papaya (Carica papaya L) yang termasuk family Caricaceae terutama yang dikonsumsi ialah daun muda bagian pucuknya di pohon. Secara umum dapatalah dikatakan bahwa Pulau Manado Tua masih memiliki daya dukung habitat untuk kehidupan dari beberapa satwa liar endemik, karana adanya hutan lindung yang diatur oleh peraturan pemerintah, sehingga dapat dikatakan bahwa wilayah Manado Tua masih memiliki habitat yang baik untuk hidupan satwa liar.Hal ini sejalan dengan apa yang dikatakan Martin et al. (2018), bahwa indikator dari habitat satwa yang baik adalah tersedianya sumber pakan yang cukup baik dari segi kelimpahan jenis maupun jumlahnya.

Di Kelurahan Manado Tua II ditemukan kuskus kerdil dan kuskus beruang yang juga sangat bervariasi dimana kuskus kerdil diperkirakan mencapai \pm 315 ekor dan kuskus beruang mencapai \pm 57 ekor, sehingga total kuskus yang ada di Kelurahan Manado Tua II mencapai \pm 372 ekor. Artinya baik kuskus kerdil maupun kuskus beruang yang masih hidup di Pulau Manado Tua berjumlah 600 ekor, dengan pola sebaran hampir merata. Diduga populasi satwa endemik kuskus di Pulau Manado Tua di tahun-tahun yang lalu mencapai sekitar 900 ekor lebih, tetapi karena terjadi perburuan dan penebangan kayu secara ilegal menyebabkan populasi dan kehidupan satwa ini terganggu. Disamping itu, kebiasaan masyarakat bahwa setiap ada kegiatan pesta maka tingkat perburuan kuskus yang adalah satwa dilindungi menjadi meningkat. Hasil wawancara tim peneliti dengan masyarakat yang ada di kedua Kelurahan Manado Tua I dan II bahwa setiap kegiatan pesta masyarakat akan mengadakan perburuan dan setiap kali perburuan per malam, kuskus yang ditangkap/ditembak berkisar antara 15-20 ekor. Pelanggaranpelanggaran ini sudah dan sering terjadi karena masyasrakat menganggap daging kuskus adalah lebih enak dan berkasiat. Menurut WCS (2000), bahwa kuskus merupakan salah satu satwa yang dilindungi di Indonesia berdasarkan PP. No. 7 tahun 1999 tentang Pengawetan Jenis Tumbuhan dan Satwa.

Keragaman hayati di Pulau Manado Tua bukan hanya fauna kuskus yang dijumpai, tetapi masih ada jenis satwa endemik yang hidup bersama-sama seperti 
monyet hitam (Macaca nigra), tangkasi (Tarsius spectrum), Ular sanca Patola (Morelia amethistina) dan beberapa jenis burung yang endemik. Salah satu faktor juga yang menyebabkan terjadinya penurunan populasi satwa endemik Sulawesi Utara termasuk kuskus yang hidup di Pulau Manado Tua adalah tingkat pendidikan masyarakat yang ada di Pulau Manado Tua umumnya hanya tamat SD sampai SMP, sedangkan untuk tamatan SMA sampai perguruan tinggi sangat keci sekali. Menurut Samawi et al. (2014), bahwa pendidikan karakter dapat dibangun melalui pembelajaran kelas atau Sekolah, kultur satuaan pendidikan, kegiatan ekstrakurikuler yang dapat menumbuhkan karakter yang baik dari seseorang. Hal ini sejalan dengan apa yang disampaikan oleh Sakti (2017), bahwa pendidikan usia anak merupakan tahapan penting di dalam pembentukan karakter dan di usia tersebut anak dapat melakukan identifikasi nilai sosial melalui proses pembelajaran. Sedangkan Rachman (2013) mengatakan karakteristik anak melalui pembelajaran interaksi sosial yang menyenangkan akan memiliki pengaruh yang positif dalam menanamkan nilai-nilai tertentu misalnya penghargaan akan keragaman mahluk hidup, manfaat serta upaya konservasinya.

Meningkatnya eksploitasi hutan diberbagai wilayah Sulawesi Utara termasuk di Pulau Manado Tua menyebabkan ekosistem satwa ini ikut terganggu, karena rendahnya daya dukung habitat dalam suatu populasi satwa akan meningkatkan persaingan dan kenaikan angka mortalitas yang berdampak pada penurunan populasi satwa. Jika hal ini terus dibiarkan, maka kuskus endemik ini akan terancam punah. Kepunahan menjadi masalah serius yang harus diperhatikan apalagi jika terjadi pada satwa-satwa endemik, oleh karena itu upaya konservasi satwa menjadi suatu hal penting yang harus dilakukan untuk mempertahankan keberlangsungan hidup satwa liar endemik yang ada di Pulau ManadoTua. Menurut Alikodra (2018) bahwa untuk mengetahui tingkat populasi dandaya dukung habitat serta aktifitas harian satwa liar, merupakan strategi yang tepat untuk meningkatkan upaya pelestarian satwa.

\section{Daya dukung habitat Kuskus di Pulau Manado Tua}

Hasil pengamatan di lapangan menunjukkan bahwa Pulau Manado Tua banyak ditumbuhi berbagai jenis vegetasi yang menunjang kehidupan kuskus endemik. Vegetasi tersebut banyak dimanfaatkan sebagai tempat beraktifitas seperti tempat mencari makan, bermain, berteduh dan juga bereproduksi. Menurut Tangian et al. (2019) bahwa Pulau Manado Tua mempunyai potensi flora yang kaya akan jenis palma, sagu woka, silar dan kelapa serta potensi fauna seperti monyet hitam Sulawesi"Yaki" (Macacanigra) dan kuskus (Ailurops ursinus), Camar (Strenia sumatrana), canga merah (Ardea Purpurea), Kowak (Nycticorax). Vegetasi tingkat pepohonan di Pulau Manado Tua dapat dilihat pada Tabel 4.

Hasil penelitian menunjukkan bahwa untuk vegetasi tingkat pohon yang ditemukan di Pulau Manado Tua sangatlah berkelimpahan, terutama yang ditemukan di Kelurahan Manado Tua II karena masyarakat yang ada masih patuh terhadap para tua-tua adat yang memberi larangan agar tidak melakukan penebangan pohon secara liar, namun bebrbeda dengan masyarakat Kelurahan Manado Tua I yang kurang memiliki rasa kepedulian terhadap lingkungan terutama kelestarian pohon di puncak gunung Manado Tua I. Di lokasi inilah banyak terjadi penebangan pohon liar dan tidak terkendali. Menurut Kinnaird (2000) bahwa kuskus mengeluarkan bau yang kuat, terkadang demikian kuatnya sampai meresap ke dalam cabang-cabang pohon yang ditinggalkannya dimana 
Tabel 4. Vegetasi Tingkat Pepohonan di Lokasi Penelitian

\begin{tabular}{llccccccc}
\hline No & Jenis Pohon & $\begin{array}{c}\mathrm{K} \\
(\mathrm{phn} / \mathrm{ha})\end{array}$ & $\mathrm{F}$ & $\begin{array}{c}\mathrm{D} \\
\left(\mathrm{m}^{2} / \mathrm{ha}\right)\end{array}$ & $\begin{array}{c}\mathrm{KR} \\
(\%)\end{array}$ & $\begin{array}{c}\mathrm{DR} \\
(\%)\end{array}$ & $\begin{array}{l}\text { FR } \\
(\%)\end{array}$ & $\begin{array}{c}\text { INP } \\
(\%)\end{array}$ \\
\hline 1 & Beringin (Ficus sp.) & 12 & 0,7 & 157,6 & 16,22 & 22,56 & 15,91 & 54,69 \\
\hline 2 & Kayu Kapuk & 14 & 0,9 & 87,5 & 18,92 & 12,53 & 20,45 & 51,9 \\
\hline 3 & $\begin{array}{l}\text { Rao (Dracontomelium } \\
\text { dao) }\end{array}$ & 6 & 0,4 & 85,7 & 8,11 & 12,27 & 9,69 & 29,47 \\
\hline 4 & $\begin{array}{l}\text { Jambu Mente (Anocordium } \\
\text { accidentale) }\end{array}$ & 16 & 0,10 & 51,6 & 21,31 & 7,72 & 21,03 & 49,16 \\
\hline 5 & Amu (Murase sp.) & 11 & 0,72 & 53,57 & 13,56 & 7,87 & 13,72 & 34,29 \\
\hline 6 & $\begin{array}{l}\text { Kayu Kambing (Garuga } \\
\text { floribunda) }\end{array}$ & 10 & 0,42 & 142 & 13,26 & 21,13 & 6,92 & 40,11 \\
\hline 7 & $\begin{array}{l}\text { Kayu Ketapang (Canarium } \\
\text { sp.) }\end{array}$ & 9 & 0,6 & 122,5 & 12,16 & 17,54 & 13,64 & 39,03 \\
\hline & $\quad 78$ & 3,84 & 700,47 & 103,54 & 101,62 & 100,76 & 298,65 \\
\hline
\end{tabular}

pepohonan biasanya digunakan sebagai tempat untuk melingkarkan ekornya agar dapat bergantung dan berpindah-pindah dari cabang pohon satu ke cabang pohon yang lain. Sedangkan menurut Wowor et al. (2016) bahwa di Tangkoko Batuangus kuskus beruang (Ailurops ursinus) banyak dijumpai diatas pohon dengan ketinggian 8$36 \mathrm{~m}$ dan sangat jarang ditemukan berjalan diatas tanah. Adapun pohon yang banyak yang dimanfaatkan satwa ini seperti pohon bugis (Koordesiodendron pinatum), pohon rao (Dracontomelodao), coro (Ficus Variegata), kayu kambing (Garuga Floribunda), ketapang (Triminalia Capata).

Penebangan pohon yang berlebihan ini menyebabkan terjadi proses perembesan dimana banyak kuskus endemik yang coba menggunakan tanaman-tanaman masyarakat di areal perkebunan untuk dijadikan tempat hidup mereka termasuk tempat mencari makanan.

Hasil penelitian ditemukan bahwa di Pulau Manado Tua, vegetasi tumbuhan yang sangat mendominasi adalah pohon beringin (Ficus sp.) yaitu mencapai indeks nilai penting $54,69 \%$. Jenis pohon inilah yang banyak dimanfaatkan kuskus endemik di Pulau Manado Tua sebagai tempat beristirahat dan bermain namun sangat kecil digunakan sebagai tempat mencari makan. Ruslan (1986) mengatakan bahwa spesies tumbuhan tertentu memiliki indeks nilai penting di atas $100 \%$, maka pohon tersebut diklasifikasikan sebagai jenis-jenis penyusun utama dari suatu komunitas utama vegetasi dan biasanya diameter pohonnya mencapai $\pm>35 \mathrm{~cm}$.

Di Pulau Manado Tua banyak dijumpai pohon-pohon seperti: pohon ketapang, beringin dan pohon mangga hutan besar dan dari hasil pengamatan ditemukan bahwa pohon-pohon tersebut banyak yang dijadikan tempat beraktifitas seperti: tempat mencari makan, tempat bermain, tempat bereproduksi serta tempat berlindung dari tiupan angina kencang. Semakin tinggi tingkat kunjungan satwa kuskus berarti semakin memberikan kenyamanan tersendiri bagi mereka. Disisi lain terlihat bahwa beberapa jenis tanaman baik tingkat sapihan atau semai cukup banyak ditemukan di Kelurahan Manado Tua I dan II. Tanaman ini tersebar cukup merata seperti jambu mente (Anacordium accidentale) dan pohon mengkudu (Mirinda citrifolia) yang oleh masyarakat setempat biasanya tanaman-tanaman ini dikembangkan sebagai tanaman sela dan obat-obatan. Gambaran tumbuhnya beragam tanaman di Pulau Manado Tua memberi arti bahwa daya dukung untuk kehidupan kuskus sangat tinggi, sehingga 
Tabel 5. Penyusun utama komunitas tanaman sapihan yang banyak dimanfaatkan oleh kuskus kerdil di Manado Tua I dan II.

\begin{tabular}{clccccccc}
\hline No & \multicolumn{1}{c}{ Jenis } & $\begin{array}{c}\mathrm{K} \\
(\mathrm{phn} / \mathrm{ha})\end{array}$ & $\mathrm{F}$ & $\mathrm{D}$ & $\mathrm{KR}$ & $\mathrm{DR}$ & FR & $\begin{array}{c}\text { INP } \\
(\%)\end{array}$ \\
\hline 1 & Enau (Arenga piñata) & 7 & 1,11 & 89 & 23,68 & 23,64 & 31,95 & 79,30 \\
\hline 2 & $\begin{array}{l}\text { Pandan hutan } \\
\text { (Pndanus sp. })\end{array}$ & 13 & 0,14 & 121 & 26,31 & 31,92 & 4,16 & 61,40 \\
\hline 3 & Pisang kapok & 10 & 1,25 & 70 & 31,58 & 18,18 & 41,21 & 90,98 \\
\hline 4 & Rumbia (Nipase sp.) & 6 & 0,72 & 112 & 17,42 & 28,00 & 22,61 & 69,00 \\
\hline & Total & 36 & 3,22 & 392 & 98,99 & 100,90 & 100,00 & \\
\hline
\end{tabular}

terlihat nyata populasi satwa-satwa tersebut terjadi peningkatan karena salah satu factor pendukungnya cukup tersedia. Sebaran tingkat vegetasi komunitas untuk tanaman tingkat sapihan dapat dilihat pada Tabel 5.

Hasil perhitungan untuk tanaman tingkat sapihan yang ditemukan di Pulau Manado Tua ternyata Nilai Indeks Pentingnya tertinggi pada tanaman pisang kapok $(90,98 \%)$. Data ini menggambarkan bahwa tingkat sebaran dan nilai pemanfaatan baik masyarakat Pulau Manado Tua dan satwa kuskus sangat tinggi. Hasil pengamatan menunjukkan bahwa banyak satwa kuskus yang memanfaatkan pisang kapok sebagai salah satu makanan mereka, tetapi harus terganggu akibat masyarakat juga sering memanfaatkan sebagai sumber makanan tambahan, apalagi ketika ada hajatan atau acara pesta kampung, maka pisang kapok sering disajikan sebagai makanan tambahan (direbus). Tapi ada beberapa jenis satwa seperti kelelawar menjadikan pisang kapok sebagai pakan utama, sehingga terjadi tumpang tindih dalam proses pencarian makanan dengan kuskus yang hidup dalam suatu areal/wilayah jelajah yang sama. Pendapat yang lain dari Kayadoe et al. (2015) menyampaikan hasil penelitian mereka bahwa kuskus menyukai buah pisang dam belimbing manis dibanding buah-buahan lainnya seperti: nangka, papaya, advokat sedangkan jenis daun yang di sukai yaitu daun matoa dan daun kayu besi pantai, daun kangkung, serta daun sawi dibanding daun kayu besi gunung dan daun ubi jalar. Menurut Alikodra (2018) bahwa proses tumpang tindih yang dilakukan secara berlebihan dan pencarian makanan di suatu wilayah tertentu merupakan gambaran ketidak cukupan persediaan makanan dialam bebas.

Tanaman tingkat sapihan yang juga banyak dijumpai di Pulau Manado Tua adalah tanaman enau (Aringa piñata) yang oleh masyarakat setempat sering digunakan baik sebagai sumber minuman tradisional dan juga digunakan sebagai bahan baku untuk pembuatan atap rumah. Di samping itu dari hasil pengamatan di lapangan menunjukkan bahwa tanaman rumbia sering juga dimanfaatkan oleh kuskus dan satwa-satwa endemik lainnya seperti jenis burung pipit, burung taong, burung radja udang. Gambaran ini juga menunjukkan bahwa sebaran vegetasi jenis Enau (Aringa pinata) dan rumbia (Nipase) cukup merata tumbuh dan tersebar dipulau Manado Tua I dan II. Secara umum daya dukung habitat untuk kehidupan satwa liar kuskus yang ditemukan di Pulau Manado Tua cukup bagus, tetapi perlu dilakukan upaya-upaya konservasi baik flora maupun fauna endemik agar tidak terjadi degradasi yang sangat berlebih sehingga kelestarian dan ekosistim di Pulau Manado Tua akan terganggu. Terganggunya ekosistem di Pulau Manado Tua akan juga berdampak pada satwa-satwa endemik lainnya. Secara umum ternyata di wilayah Manado Tua 
Tabel 6. Satwa liar endemik yang ditemukan di Pulau Manado Tua I dan II

\begin{tabular}{ccll}
\hline No. & Lokasi Pengamatan & \multicolumn{1}{c}{ Jenis Satwa } & \multicolumn{1}{c}{ Jumlah (ekor) } \\
\hline 1. & Manado Tua I & - Ular patola & $<20$ ekor \\
& - Rusa & $>31$ ekor \\
& - Burung air & $>50$ ekor \\
& - Maleo kecil & $>210$ ekor \\
& - Monyet hitam & $>42$ ekor \\
& & \\
& & \\
& Manado Tua II & - Tarsius spectrum & $>65$ ekor \\
& & - Burung kwak ${ }^{2}$ & $>125$ ekor \\
& & - Burung cui & $>225$ ekor \\
& & - Burung kum ${ }^{2}$ & $>125$ ekor \\
\hline
\end{tabular}

Sumber : Hasil wawancara dengan masyarakat (2015)

menyimpan juga beberapa jenis satwa endemik seperti yang terlihat pada Tabel 6 .

Hasil ini menunjukkan bahwa diwilayah Pulau Manado Tua selain satwa endemik kuskus baik yang ursinus maupun Stregoccuscus celebensis, masih juga hidup beberapa jenis satwa yang dilindungi. Gambaran ini menunjukkan bahwa daya dukung habitat yang dijumpai di Pulau Manado Tua masih memungkinkanhidup secara berdampingan antara satwa, namun secara ilmiah tumpang tindih dalam hal penggunaanwilayah untuk beraktifitas baik mencari makan sampai bereproduksi belum pernah diteliti. Hal ini dimaksudkan untuk menjamin keseimbangan ketersediaan makanan yang dapat menunjang kelangsungan hidup dari masing-masing satwa endemik. Walaupun sudah ada undang-undangkonservasi No.5 tahun 1990 untuk menjaga kelestarian dari satwa-satwa yang ada tetapi banyak masyarakat tidak mematuhi, sehingga penangkapan satwasatwa endemik secara liar tetap berlangsung secara tak terkendali. Ketidaktersediaan pakan yang kurang mencukupi sering pula terjadi proses perembasan, dimana banyak satwa-satwa liar seperti: Macaca, rusa, jenis burung berbadan besar yang sering memanfaatkan perkebunan masyarakat sebagai tempat mencari makanan demi kelangsungan hidup mereka. Masyarakat setempat menganggap peristiwa tersebut sebagai bentuk ledakan populasi dan hama bagi usaha perkebunan mereka, karena dari hasil pengamatan dan wawancara dengan masyarakat dikatakan bahwa besaran populasi satwa-satwa liar endemik di Pulau Manado Tua sangat mempengaruhi usahausaha perkebunan mereka.

\section{KESIMPULAN DAN SARAN}

\section{Kesimpulan :}

Berdasarkan hasil analisis data dan pembahasan semua variabel penelitian maka dapat disimpulkan bahwa populasi satwa endemik kuskus kerdil masih ditemukan di Pulau Manado Tua I dan II, namun populasinya semakin menurun akibat pengrusakan daya dukung habitatnya dan penangkapan yang tak terkendali oleh masyarakat.

\section{Saran :}

Ada beberapa hal dari hasil penelitian untuk disarankan :

1. Perlu lebih difungsikan para petugas KSDA dalam mendukung kelestarian fauna dan flora endemik sebagai keseimbangan ekosistim.

2. Perlu suatu pemodelan wilayah konservasi yang dikembangkan oleh pihak Pemerintah dengan para Akademisi untuk menunjang kelestarian kehidupan satwa ${ }^{2}$ liar endemik yang hidup di Pulau Manado Tua dan dibentuk zona²/pembagian wilayah konservasi berbasi Ekowisata fauna langka endemik. 


\section{DAFTAR PUSTAKA}

Alikodra, H. S. 2018. Teknik Pengelolaan Satwaliar: Dalam rangka mempertahankan keanekaragaman hayati Indonesia. PT Penerbit IPB Press.

Darenoh, C., E. de Queljoe dan R. Butarbutar. 2019. Aktivitas diurnal kuskus beruang betina (Ailurops ursinus) di Pusat Penyelamatan Satwa Tasikoki Minahasa Utara. Jurnal Bios Logos 9(1):8-14.

Handayani, S. K. dan R.M. Kunda. 2019. Identifikasi jenis-jenis tumbuhan sebagai pakan kuskus (Phalangeridae) asal Maluku di Taman Nasional Manusela bagian Utara Kabupaten Maluku Tengah. Jurnal Matematika Sains dan Teknologi 20(1):9-19.

Kayadoe, M., S. Sinaga, A. Rochana dan U.H. Tanuwiria. 2020. Kajian kualitas fisik ransum pelet dalam upaya rekayasa ransum bagi Kuskus Bertotol Biasa. Jurnal Sain Peternakan Indonesia 15(1):7-17.

Kinnaird, M.F. 2000. Sulawesi Sebuah Panduan Sejarah Alam. Volume ke-1. Yayasan Pengembangan Wallaca. Jakarta.

Kiroh, H. dan Tigor Gultom. 2006. Mengenal Tingkah Laku Makan Kuskus Beruang (Ailurops ursinus) di Cagar Alam Tangkoko (PraPenelitian). Program Minat Konservasi Satwa Langkah Endemik. Fakultas Peternakan Universitas Sam Ratulangi.

Maramis, M. A., B. Wagey, A.P. Rumengan, C.F. Sondak, E.T. Opa dan K.F. Kondoy. 2020. Karbon pada padang lamun di perairan pulau manado tua. Jurnal Pesisir Dan Laut Tropis 8(2):79-91.

Martin, T. E., J. Monkhouse, D.P. O'Connell, K. Analuddin, A. Karya, N.E. Priston dan D.G. Tosh. 2019. Distribution and status of threatened and endemic marsupials on the offshore islands of south-east Sulawesi, Indonesia. Australian Mammalogy 41(1):76-81.

Rachman, M. 2013. Pengembangan pendidikan karakter berwawasan konservasi nilai-nilai sosial. FIS (40): $1-15$.

Ruslan, M. (1986). Studi perkembangan suksesi pada hutan alam sekunder di daerah hutan pendidikan Fakultas Kehutanan Unlam Mandiangin Kalimantan Selatan.

Samawi, A., M.A.M. Arafiq dan L. Hidayah. 2014. Model pendidikan karakter yang baik (Studi Lintas Situs Bests Practices) pendidikan karakter di SD. Sekolah Dasar: Kajian Teori dan Praktik Pendidikan, 23(2):

Sakti, B.P. 2017. Indikator pengembangan karakter siswa Sekolah Dasar. Magistra Unwidha Klaten 30(1):110.

Schelinck, H.M; David P.C; Richard E.B. 2010. Advences in the Study of Behavior. Burlington, Academic Press.

Sara, M., B. Bachtiar dan D. Puspaningrum. 2020. Perilaku harian Kuskus Beruang (Ailurops ursinus) di Kawasan Konservasi Cagar Alam Tangale. Jurnal Penelitian Kehutanan BONITA 2(1):20-26.

Saragih, E.W., M.J. Sadsoeitoeboen dan F. Pattiselanno. 2010. The diet of spotted cuscus (Spilocuscus maculatus) in natural and captivity habitat. Nusantara Bioscience 2(2): 78-83

Saroyo, S., P. Siahaan, M. Langoy dan R. Koneri. 2019. Pendidikan konservasi satwa endemik sulawesi bagi siswa Sekolah Dasar di Kelurahan Batuputih Bawah, Kecamatan Ranowulu, Kota Bitung, Sulawesi Utara. VIVABIO: Jurnal Pengabdian Multidisiplin 1(3):26-31.

Sunarto, 1996. Pembagian sumberdaya di antara Burung-burung Rajaudang di Cagar Alam Tangkoko-Dua Saudara (Laporan Penelitian). Fakultas 
Zootec Vol. 41 No. 1 : 291 - 302 (Januari 2021) pISSN 0852 - 2626 eISSN 2615 - 8698

Biologi Universitas Indonesia. Jakarta

Tangian, D., B.D. Polii dan S.M. Mengko. 2019. Analisis potensi daya tarik wisata Kota Manado. In Seminar Nasional Komunitas dan Kota Berkelanjutan (Vol. 1, No. 1, pp. 192200).

Usmany, M., dan P. Kakisina. 2018. Identifikasi tumbuhan sumber pakan dan tingkat palatabilitas Kuskus (Famili Phalangeridae) di desa Lumoli, Seram, Maluku. Jurnal Kajian Veteriner 6(1):17-30.

Wildlife Conservation Society. 2000. Cagar Alam Tangkoko - Dua Saudara Sulawesi Utara. Indonesia. Survey Biology, Patroli, Monitoring dan Rekomendasi Pengelolaan. Wildlife Conservation Society - Indonesia. Program Manado.

Wowor, F.M., H.J. Kiroh, V. Rawung, R.H. Wungouw. 2016. Estimasi kepadatan Kuskus Beruang (Ailurops ursinus) Di Cagar Alam Tangkoko Batuangus Kota Bitung. Jurnal Zootek 36(2): 395-404 